\title{
Research on Loading System of the Rail Vehicle Bogie Test Bed
}

\author{
Ning Lu', Li Na Ren ${ }^{1}$ and Zhong Wei Chen ${ }^{1}$ \\ ${ }^{1}$ School of Mechanical-electronic and Automobile Engineering, BUCEA, China
}

\begin{abstract}
The bogie is one of the most important parts of metro vehicles, to provide traction, support and guidance of the vehicle in the process of the vehicle. To a great extent, the rationality of the structure of the bogie can directly affect the dynamic performance of the metro vehicles and the safety and comfort of the ride. This paper researches on the detection equipment of the Metro Bogie, mainly researches on the loading system of the metro static load test bed.
\end{abstract}

\section{Introduction}

With the rapid development of China's economy and the increase of urban population, the pressure on urban public transport is becoming larger. The metro is an important part of urban public transport and plays an important role in easing traffic congestion and other issues. The bogie is one of the most important parts of metro vehicles, to provide traction, support and guidance of the vehicle in the process of the vehicle. To a great extent, the rationality of the structure of the bogie can directly affect the dynamic performance of the metro vehicles and the safety and comfort of the ride[1]. This paper research on the detection equipment of the Metro Bogie, mainly research on the loading system of the metro static load test bed, has the actual application value, can improve the vehicle running safety and comfort, and will promote the development of metro maintenance in our country.

\section{Composition of the test bed}

The test bed consists of the following components: mechanical system, hydraulic systems, electrical control systems.

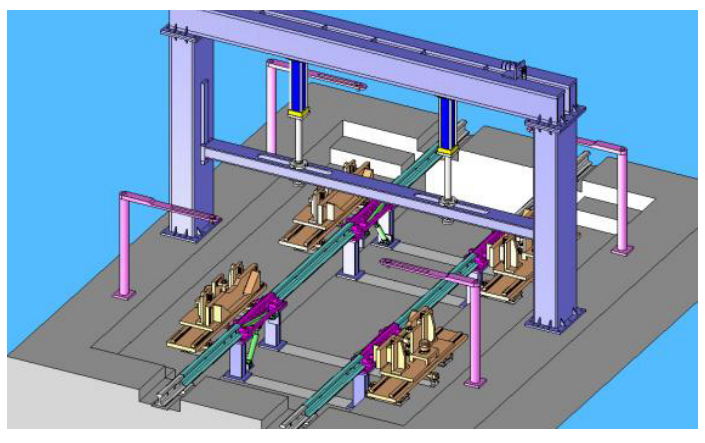

Figure 1. Electro-hydraulic servo double actuators rail vehicle bogie test bed.

\subsection{Mechanical system}

Mechanical system is composed of fixed transom door frame, bogie centering device, weight measurement units. Fixed transom door frame is a structural steel frame. Bogie centering device is set in one side of the standard track. Weight measurement units are core part of the test bed, and the units are the introduction of China's railway technical authorities newly developed system weighing units, which can entirely monitor the wheel weight during the bogie is loaded, weighing data bus transferring to the computer.

\subsection{Hydraulic systems}

Hydraulic station is the hydraulic power source of the entire system. It is installed in the vicinity of the gantry, the tubing along the column and beam receiving cylinder[2]. The hydraulic pressure source is provided with a cooling cycle apparatus. Hydraulic station is in accordance with the relevant provisions in order to meet the requirements of the servo system for cleaning, installation, to ensure the normal operation of the various parts of the hydraulic systems.

The device is installed two ram cylinders, cylinder stroke $400 \mathrm{~mm}$, and single cylinder is greater than the maximum output pressure $200 \mathrm{KN}$. Import displacement sensors are in the cylinder, and import force sensor is connected to the piston rod end. Pressing cylinder uses the method of electro-hydraulic servo intelligent control to achieve load control and displacement control, which can simulate vehicle coordination loaded in the case of partial load.

\subsection{Electrical control systems}


The control of the test bed is composed of a remote computer cabinets and site electrical control cabinet, including the hardware of the remote computer cabinet consists of: industrial control computers, monitors, UPS uninterruptible power supply, A4 printer and the corresponding buttons and lights; by means of configuration software operation cabinet to complete the test bed data storage, graphics, data reporting, query and printing. Site electrical control cabinet consists of a DC power supply, PLC modules, data acquisition modules scene, analog data output modules and other components, which mainly achieve the function of site control actuator, sensor signal detection and processing, fault information collection and more. Operation platform and control cabinet have a reliable ground, zero connection protection, terminal blocks using high-quality insulating material. Control systems have the functions of overload, overcurrent, overvoltage, overheating, under voltage, short circuit, lack of equal protection. Operation platform and control cabinets are equipped with an emergency stop button.

\section{Loading system composition}

The loading system adopts hydraulic loading. Basis of hydraulic loading method is that the motor provides the power source, then the hydraulic pump to convert mechanical energy into pressure energy to drive the hydraulic oil, by changing the valve opening direction or the size of the opening to control the flow of hydraulic oil and flow, makes the hydraulic cylinder can make different reaction route and action to complete the system needed to travel or movement[3].

The loading system of the static load test platform of the Metro Bogie is composed of 2 sets of hydraulic cylinders, 2 servo valves, 2 pressure sensors and 2 displacement sensors. The hydraulic cylinder is connected to the movable beam by the front flange, the hydraulic cylinder is $500 \mathrm{~mm}$, and the built-in displacement sensor is adopted to reduce the influence of environmental factors. The hydraulic cylinder can be moved automatically on the movable beam, and the adjustment range is $500 \sim 2000 \mathrm{~mm}$. The displacement control or the force loading is set by the industrial computer, and the loading results are displayed in the monitoring interface in real time, the equipment can be loaded synchronously, and can be loaded separately.

\section{Loading system working principle}

The working principle of this system is that the loading system is a closed-loop system. First, the required displacement is provided by the industrial computer, hydraulic pump provides power for hydraulic cylinder and servo valve, the input signal of the displacement sensor is compared with the input signal provided by the industrial computer. Then the signal is transmitted to the servo valve to control the opening size of the valve core. Thus, the oil flow rate of the hydraulic cylinder is controlled, so as to achieve the control of the displacement, and the actual displacement size is fed back to the industrial computer through a displacement sensor arranged on the hydraulic cylinder.

There are two kinds of synchronization control strategies of the system, the same way and the masterslave mode. Master-slave mode refers to multiple hydraulic cylinder synchronous control, one hydraulic cylinder is selected as the active cylinder, output active cylinder set as output, other hydraulic cylinder for the slave cylinder, common active cylinder electro-hydraulic valve, cylinder driven selection of electro-hydraulic servo valve, cylinder driven with active cylinder movement the same way refers to the synchronization control; pre setting an ideal input, a plurality of hydraulic cylinders and tracking operation to achieve synchronous control. In the same way, it can eliminate the interaction between the hydraulic cylinders, and do not need to adjust the running of the hydraulic cylinder, so the time needed to realize the synchronization is short, and the dynamic performance of the system is better. Therefore, the system uses the same control strategy

The same type of displacement synchronous control system structure as shown in Figure 4-8, control the use of two controller, while tracking the same amount of input, and then the two loop respectively according to the difference between the actual input and output adjustments, two circuits do not interfere with each other, their control, effectively eliminate the influence of two loops. The system can be in a very short period of time to make adjustments and achieve synchronization output.

The main technical indexes of the system are:

1) Single channel maximum loading capacity: 15 tons;

2) Servo cylinder displacement measurement range: $0-500 \mathrm{~mm}$, system accuracy $0.1 \% \mathrm{~F} . \mathrm{S}$;

3) The lifting speed of the cylinder: $60 \sim 200 \mathrm{~mm} /$ min, adjustable at any time, can work continuously;

4) Load measurement accuracy: 0.1\%F.S;

5) Displacement measurement accuracy: $0.1 \% \mathrm{~F} . \mathrm{S}$;

6) The working environment temperature: -20 to +45 DEG C.

According to the working principle and work requirements, the system design proposal, select the appropriate hydraulic components. As shown in Table 1.

Table 1 Components models

\begin{tabular}{c|c|c}
\hline Name & Model & Quantity \\
\hline Servo valve & R02KO1M0NSP2 & 2 \\
\hline $\begin{array}{c}\text { Hydraulic } \\
\text { cylinder }\end{array}$ & $\begin{array}{c}\text { USYWF10 } \phi_{125} \times \\
500-25 L H A\end{array}$ & 2 \\
\hline $\begin{array}{c}\text { Displacement } \\
\text { sensor }\end{array}$ & LWF-500-A1 & 2 \\
\hline Force sensor & DBSL20T & 2 \\
\hline Hydraulic pump & A3H16-FRO1KK- \\
10
\end{tabular}




\begin{tabular}{c|c|c}
\hline One-way valve & S8A3.0/2 & 1 \\
\hline Relief valve & DBDS6P10/31.5 & 1 \\
\hline Tank & SS304 & 1 \\
\hline Accumulator & S50250S-A & 1 \\
\hline
\end{tabular}

\section{Simulation experiment}

This paper will also take trying to determine the parameters of PID: the process of trying in the parameters according to the variation tendency of the system to adjust, first with proportional coefficient adjustment, and then adjusting the integral coefficient, finally by differential coefficient adjustment. First adjust the proportion coefficient, integral time adjustment to infinity, the differential time is adjusted to 0 , the proportion coefficient from adjusting observation curve, if serious oscillation increases proportional coefficient, if serious overshoot decreases proportional coefficient, $4: 1$ curve to stop; then by adjusting the integral coefficient, if only use ratio can not eliminate static error coefficient regulation requires the use of integral coefficient adjustment, first set a larger integration time value, adjusted from large to small, if volatility increases the integral time value, if the deviation from the given value is reduced, the integral time value. Adjust the proportion coefficient during May, in order to achieve better control effect; finally, differential coefficient adjustment, if the proportion coefficient and integral coefficient after repeated adjustment has not reached the desired effect, the need for differential adjustment, the differential time is set to 0 , if the system has high overshoot and long time is required to reach a steady state on the contrary, increase the differential time, decrease the differential time during this period can also adjust the proportion coefficient and integral coefficient, the ideal curve, to achieve the control effect[4].

The fuzzy PID controller selection fuzzy controller displacement control system and its control principle is: according to the deviation and deviation change displacement input displacement value rate, according to the fuzzy rules set for correction of PID parameters.

Displacement control system, fuzzy PID controller, parameter tuning principle: Based on the repeated tests of the displacement control system, the deviations of the system, the variation rate of the deviation, the coefficient of proportionality, the integral coefficient and the coefficient of differentiation are obtained, and summarized as follows: When the displacement control system of displacement deviation of $|\mathrm{e}|$ is large, should take a larger value to the system response speed, but should not be too large, otherwise it will make the system unstable; should take a smaller value to prevent the system out of control at first, if the overshoot can be removed more points. When the displacement deviation of displacement control system is equal to $|\mathrm{e}|$, smaller values should be taken to obtain smaller overshoot, and the values should be selected appropriately to speed up the response, while the value should be increased in an appropriate range. When the displacement deviation of displacement control system is less than $|e|$, in order to make the system stable, we should select the larger sum and select the appropriate one to reduce oscillation[5].

The fuzzy subsets of input and output are defined as: $\{\mathrm{NB}, \mathrm{NM}, \mathrm{NS}, \mathrm{Z}, \mathrm{PS}, \mathrm{PM}, \mathrm{PB}\}$, respectively, representing negative, large, negative, middle, negative, small, zero, positive, small, middle, and large.

The domain of definition of input and output for input: e, domain EC: $\{-3,-2,-1,0,1,2,3\}$; domain output: $\{-3$, $2,-1,0,1,2,3\}$; domain: $\{-0.6,-0.4,-0.2,0,0.2,0.4,0.6\}$; domain: $\{-0.06,-0.04,-0.02,0,0.02,0.04,0.06\}$;

The deviation of the basic domain of $[-10,10] \mathrm{mm}$, basic theory, deviation rate of change EC domain [-0.5, $0.5] \mathrm{mm} / \mathrm{s}$, quantization factor calculated deviation $\mathrm{E}$ and deviation change rate of $\mathrm{EC}$, respectively, the output, the scale factor, respectively, $\mathrm{K} 1=1, \mathrm{~K} 2=1 / 5, \mathrm{~K} 3=1 / 50$.

Co simulation of displacement control system is used in AMESim and Simulink, establish the model of hydraulic system in hydraulic system simulation has advantages in AMESim, with the establishment of control system model of the advantages of the Simulink in control system simulation.
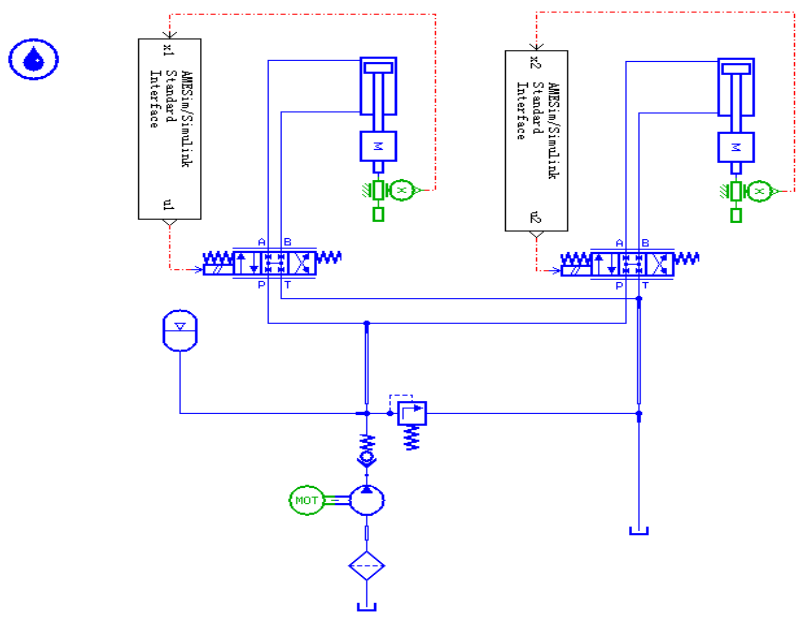

Figure 2. Displacement control hydraulic system model built in AMESim

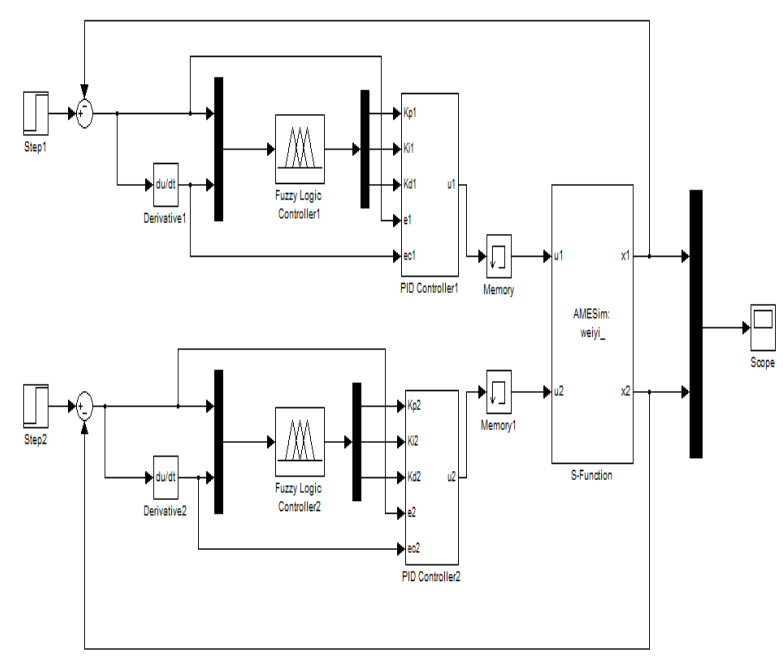

Figure 3. Fuzzy PID control system model built in Simulink 


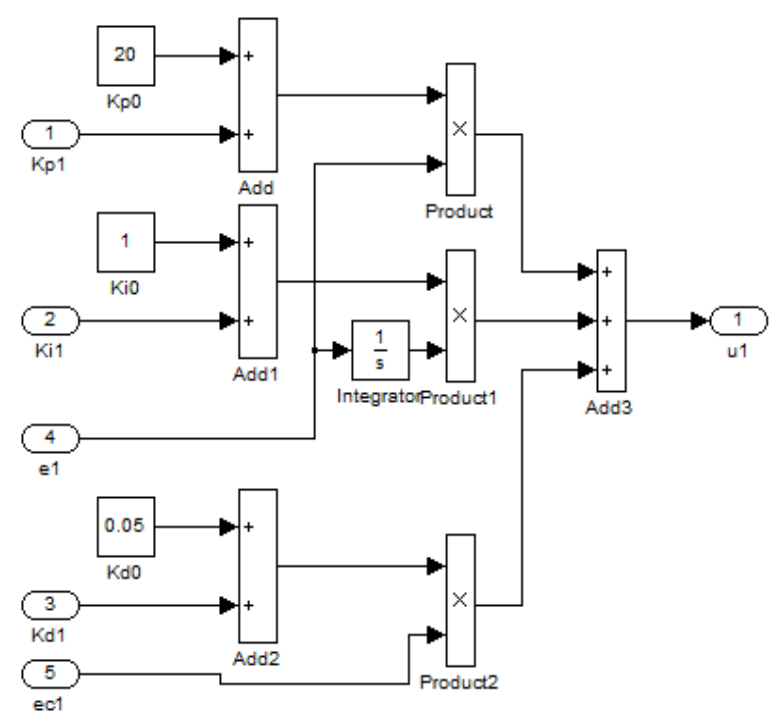

Figure 4. PID controller structure

The initial parameters of the PID control structure of fuzzy PID controller are set up $K_{p}=20, K_{i}=1, K_{d}=0.05$, and simulation is carried out to get the step response curve of the fuzzy PID control, as shown in figure5, the displacement error curves of the two hydraulic cylinders are shown in figure6.

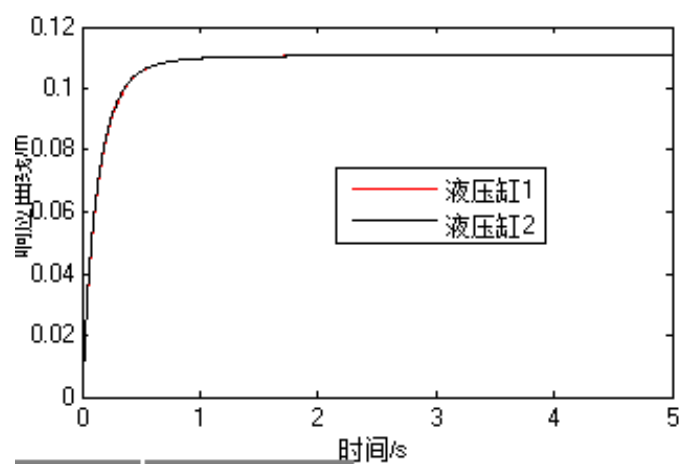

Figure 5. Fuzzy PID control step response curve of displacement control system

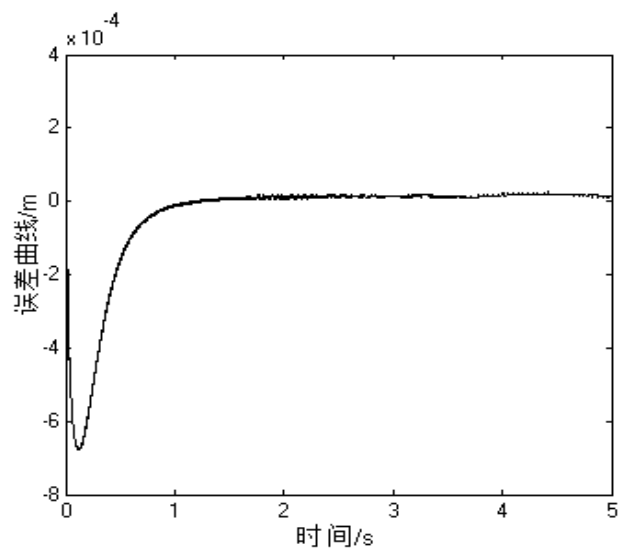

Figure 6. Displacement error curve of two hydraulic cylinders
From the above two figure can be seen, the use of fuzzy PID synchronous control, hydraulic cylinder 1 and the hydraulic cylinder 2 displacement can reach steady state in about $1 \mathrm{~s}$, fast response speed, and according to the error curve can also be seen to achieve good synchronization effect.

\section{References}

1. Chr Angeli, An online expert system for fault diagnosis in hydraulic systems J. Expert System. vol. 2, pp. 115-119, 1999.

2. M Lizell, Dynamic leveling a low power active suspension with adaptative control J. Vehicle System Dynamics. vol. 3, 1991.

3. Marquis-Favre, W.Bideaux, E.Scavarda. A planar mechanical library in the AMESim simulation software[J]. Formulation of dynamics equations, Simulation modeling practice and theory.2006,14( 1 ):25-46.

4. Edik Arakeljan, Mark Panko, Vasili Usenko. Comparative Analysis of Classical and Fuzzy PID Algorithms[J]. Advances in Soft Computing.2000,6: 206-212.

5. X.C. Liu, Q.T Huang \& D.C. Cong. New modeling and analysis of three-stage electro-hydraulic servo valve. 2008 International Workshop on Modeling[J]. Simulation and Optimization.2008,8:146-150. 